\title{
Metabolic Syndrome and Prevalent Any-site, Prostate, Breast and Colon Cancers in the U.S. Adult Population: NHANES 1999-2010
}

\author{
Thirumagal Kanagasabai ${ }^{1}$, Jason X. Nie ${ }^{1}$, Caitlin Mason ${ }^{2}$ and Chris I. Ardern ${ }^{1 *}$ \\ ${ }^{1}$ School of Kinesiology and Health Science, York University, Toronto, Ontario, Canada \\ ${ }^{2}$ University of Washington Health Promotion Research Center, Seattle, Washington, USA
}

\begin{abstract}
Background: Metabolic Syndrome (MetS) is associated with elevated risk of diabetes, cardiovascular disease, and premature mortality. To date, however, the association between MetS and obesity-related cancers has not been systematically assessed within a population-based sample.
\end{abstract}

Methods: In order to quantify the association between MetS and its components on any-site, breast, prostate, and colon cancers, data from the U.S. NHANES 1999-2010 ( $n=15141,18-85$ years) were used

Results: In general, the prevalence of MetS was higher amongst those with a self-reported history of cancer. Although MetS, its individual components, and total number of components were positively related to odds of any-site, breast, prostate, and colon cancers, this effect was almost entirely eliminated after adjustment for age. In age-adjusted models, elevated blood glucose was associated with higher odds of prostate (OR: $1.67,95 \% \mathrm{Cl}: 1.08-2.56$ ) and colon cancer (OR: $1.60,95 \% \mathrm{Cl}: 1.02-2.53$ ), and a protective effect of low HDL cholesterol on prostate cancer (OR: $0.64,95 \% \mathrm{Cl}: 0.43-0.94)$. Further adjustment for sex, ethnicity, income, education, smoking, alcohol, and recreational/ leisure-time physical activity had only minimal influence on these associations. In multivariable analyses, no uniform linear trends were observed between the number of MetS components and site-specific cancers.

Conclusion: After accounting for covariates, no consistent association between MetS and any-site, breast, prostate, or colon cancer was observed. Further prospective study is necessary to confirm and extend our understanding of the role of age and other risk factors on the inter-relationship between metabolic health and cancer.

Keywords: Metabolic syndrome; Cancer; Any-site cancer; Prostate cancer; Breast cancer; Colon cancer and aging

\section{Introduction}

Metabolic syndrome (MetS) currently affects approximately onethird of U.S. adults, and is disproportionately experienced by older individuals, women, and those with excess weight [1,2]. Obesity, as a central component of MetS, is also associated with oxidative stress, which is on the causal pathway of several age-related diseases, including cardiovascular disease, diabetes and cancer $[3,4]$. Because aging is associated with increased oxidative stress and inflammation, free radical and immunological theories suggest a relationship between MetS and several types of cancer [5-7]. Although the relationships between MetS, obesity, and cancer survival are complex, a protective effect of physical activity and low sedentary behaviour and cancer has been demonstrated [8].

In a recent meta-analysis, men with MetS had a greater relative risk of liver $(43 \%)$, colorectal $(25 \%)$, and bladder $(10 \%)$ cancers, but decreased prostate cancer risk (29\%) compared to those without MetS. In the same study, women with MetS had increased pancreatic (58\%), postmenopausal breast (56\%), colorectal (34\%) and endometrial (61\%) cancer risk [9]. Reviews that have focused on individual MetS components (e.g. "overt diabetes", "pre-eclampsia" and obesity) have reported mixed results, and may be accounted for in part due to variation in study design, MetS criteria, and population of interest [1016]. Similarly, a number of cohort and case-control studies have also assessed whether cancer risk varies according to the number of MetS components, yielding inconsistent results [17-22]. As with the studies of MetS overall, these investigations have largely focused on a select group of cancers, and none have explored the association within nationally representative data that allows for generalization to a geographically and demographically diverse sample of the U.S. population.

The purpose of this study was to therefore quantify the association between MetS (overall, number, and individual components), and any- site, breast, prostate and colon cancers in multiple cycles of the U.S. National Health and Nutrition Examination Survey (NHANES).

\section{Methods}

\section{Participants}

The U.S. NHANES was designed to assess the health and nutritional status of adults and children in the United States, details of which can be found elsewhere [1,8]. The initial sample included 62, 160 individuals from 1999-2010 [1999-00: $\mathrm{n}=9$ 965; 2001-02: $\mathrm{n}=11039$ 2003-04: $\mathrm{n}=10$ 122; 2005-06: $\mathrm{n}=10$ 348; 2007-08: $\mathrm{n}=10$ 149; 2009-10: $\mathrm{n}=10$ 537]. Subsequent exclusions were made for age $(<18 \mathrm{y}: \mathrm{n}=26781)$ and missing data for MetS components $(\mathrm{n}=20238)$, for a final analytic sample of 15,141 [age 18-85 y; 1999-00: $\mathrm{n}=2$ 175; 2001-02: $\mathrm{n}=2$ 449; 2003-04: $\mathrm{n}=2$ 450; 2005-06: $\mathrm{n}=2$ 485; 2007-08: $\mathrm{n}=2$ 847; 2009-10: $\mathrm{n}=2$ 735].

\section{Metabolic Syndrome}

MetS was defined according to the Harmonized Criteria which classifies MetS on the basis of three or more of the following: waist circumference $\geq 102 \mathrm{~cm}$ (men) and $\geq 88 \mathrm{~cm}$ (women); triglyceride $\geq 1.69$

*Corresponding author: Chris I. Ardern, School of Kinesiology and Health Science, 352 Norman Bethune College, York University, 4700 Keele Street Toronto, ON M3J1P3, Canada, Tel: 416736 2100; E-mail: cardern@yorku.ca

Received February 08, 2014; Accepted February 27, 2014; Published March 05 2014

Citation: Kanagasabai T, Nie JX, Mason C, Ardern Cl (2014) Metabolic Syndrome and Prevalent Any-site, Prostate, Breast and Colon Cancers in the U.S. Adult Population: NHANES 1999-2010. J Metabolic Synd 3: 135. doi:10.4172/21670943.1000135

Copyright: $\odot 2014$ Kanagasabai T, et al. This is an open-access article distributed under the terms of the Creative Commons Attribution License, which permits unrestricted use, distribution, and reproduction in any medium, provided the original author and source are credited. 
$\mathrm{mmol} / \mathrm{L}$ (mM); HDL-cholesterol < $1.04 \mathrm{nM}$ (men), $1.29 \mathrm{mM}$ (women); blood pressure $(\mathrm{BP} \geq 130 / 85 \mathrm{mmHg}$ of either diastolic or systolic pressures; and fasting plasma glucose $\geq 5.6 \mathrm{mM}$ [23]. Participants who self-reported the use of medications for blood pressure, cholesterol, or diabetes were identified as having high blood pressure, dyslipidaemia, and high fasting glucose, respectively.

\section{Cancer}

Cancer history (yes/no) was based on a single-item self-report ('has a physician or health professional ever told you that you have a cancer or malignancy of any kind'?). Participants who responded 'yes' were then asked to report the specific type of cancer.

\section{Covariates}

On the basis of previous literature, the following were included as covariates in our analyses [24]. Total physical activity level was based on physical activity due to house/yard work, transportation and recreational/leisure-time activities. Physical activity was quantified in Metabolic Equivalent (MET) min/week from self-reported physical activity data. To calculate MET min/week, moderate and vigorous activities were assumed to have $4 \mathrm{MET}$ and $8 \mathrm{MET}$ energy expenditure values, respectively [25]. One MET is equivalent to the amount of oxygen consumed while in a sitting position at rest. Physical activity was then categorized as "inactive" (no reported physical activity data), "somewhat active" ( $<500$ MET min/week) and "active" ( $\geq 500$ MET $\mathrm{min} /$ week) [25].

Positive smoking history was defined as self-reported current smoking or having smoked $\geq 100$ cigarettes in one's life. Body Mass Index (BMI; $\mathrm{kg} / \mathrm{m}^{2}$ ) was classified as normal weight $(18.5-24.9 \mathrm{~kg} /$ $\left.\mathrm{m}^{2}\right)$, overweight $\left(25-29.9 \mathrm{~kg} / \mathrm{m}^{2}\right)$, or obese $\left(\geq 30 \mathrm{~kg} / \mathrm{m}^{2}\right)$ on the basis of measured height and weight. Highest educational attainment was coded as less than high school, high school, or college; and, household income as $<\$ 20,000, \$ 20,000-44,999$, and $\geq \$ 45,000$ [19]. Alcohol intake was considered high if an individual reported having $\geq 3$ drinks per day [21].

\section{Statistical Analyses}

The prevalence of MetS and its individual components, as well as the number of MetS components present $(0,1,2,3,4$, or 5$)$ was determined for the U.S. adult population. The prevalence of MetS among individuals with breast, prostate, colon, and "any" cancer group was also estimated. Mean and standard error (for continuous variables), and percentage and percent standard error (for categorical variables) were determined according to MetS status. Differences in the demographic and behavioural characteristics of participants with and without MetS were assessed by independent t-tests and $\chi 2$ analyses, as appropriate.

Logistic regression was used to estimate the crude, age, and multivariable adjusted (with and without age) odds ratios (OR) and 95\% Confidence Intervals (CI) for the relationship between MetS (overall, individual components, and total number of components) and any-site, breast, prostate and colon cancers. Using a linear trend analysis, the relationship between number of MetS components and cancer history was subsequently assessed. All analyses were weighted to be representative of the U.S. adult population using SAS v9.3 (Cary, NC, U.S.A). Statistical significance was set at $\alpha<0.05$.

\section{Results}

Table 1 describes characteristics of the U.S. adult population by MetS status. In general, participants with MetS were older, had lower

\begin{tabular}{|c|c|c|c|c|}
\hline \multirow{2}{*}{ Characteristics } & \multirow{2}{*}{ Categories } & No MetS & MetS & \multirow{2}{*}{$\begin{array}{c}P \\
\text { value }\end{array}$} \\
\hline & & $(n=9,003)$ & $(n=6,138)$ & \\
\hline \multicolumn{2}{|c|}{ Age (Mean (SEM)) } & $41.8(0.3)$ & $53.9(0.3)$ & $<0.05$ \\
\hline Age categories & $\leq 50$ years & $72.1(0.9)$ & $41.3(1.0)$ & \multirow{2}{*}{$<0.05$} \\
\hline$(\%(\mathrm{SE}))$ & $>50$ years & $27.9(0.9)$ & $58.7(1.0)$ & \\
\hline \multirow{2}{*}{$\operatorname{Sex}(\%(\mathrm{SE}))$} & Males & $48.7(0.6)$ & $49.0(0.8)$ & \multirow{2}{*}{ NS } \\
\hline & Females & $51.3(0.6)$ & $51.0(0.8)$ & \\
\hline \multirow{2}{*}{ Ethnicity (\% (SE)) } & White & $69.7(1.2)$ & $72.7(1.6)$ & \multirow{2}{*}{$<0.05$} \\
\hline & Non-white & $30.3(1.2)$ & $27.3(1.6)$ & \\
\hline \multirow{3}{*}{$\begin{array}{l}\text { Education } \\
(\%(\mathrm{SE}))\end{array}$} & Less than high school & $17.3(0.7)$ & $24.3(0.8)$ & \multirow{3}{*}{$<0.05$} \\
\hline & High school & $23.1(0.7)$ & $28.5(1.0)$ & \\
\hline & College & $59.6(1.1)$ & $47.2(1.2)$ & \\
\hline \multirow{3}{*}{ Income (\% (SE)) } & $<\$ 20,000$ & $17.9(0.8)$ & $23.3(0.9)$ & \multirow{3}{*}{$<0.05$} \\
\hline & $\$ 20,000-44,999$ & $29.5(0.8)$ & $33.7(1.1)$ & \\
\hline & $\geq \$ 45,000$ & $52.6(1.0)$ & $43.0(1.3)$ & \\
\hline \multirow{3}{*}{$\begin{array}{c}\text { Total Physical Activity } \\
(\%(\text { SE) })\end{array}$} & Inactive & $14.2(0.5)$ & $23.8(1.0)$ & \multirow{3}{*}{$<0.05$} \\
\hline & Somewhat active & $24.2(0.7)$ & $26.3(0.9)$ & \\
\hline & Active & $61.6(0.8)$ & $49.9(1.1)$ & \\
\hline \multirow{3}{*}{$\begin{array}{c}\text { Transportation related } \\
\text { Physical Activity (\% } \\
\text { (SE)) }\end{array}$} & Inactive & $73.1(0.9)$ & $79.7(0.8)$ & \multirow{3}{*}{$<0.05$} \\
\hline & Somewhat active & $17.8(0.7)$ & $13.7(0.7)$ & \\
\hline & Active & $9.1(0.5)$ & $6.6(0.4)$ & \\
\hline \multirow{3}{*}{$\begin{array}{l}\text { House/Yard Word } \\
\text { Physical Activity (\% } \\
\text { (SE)) }\end{array}$} & Inactive & $40.0(0.9)$ & $43.4(1.1)$ & \multirow{3}{*}{$<0.05$} \\
\hline & Somewhat active & $28.1(0.7)$ & $27.4(1.0)$ & \\
\hline & Active & $32.0(0.8)$ & $29.2(1.0)$ & \\
\hline \multirow{3}{*}{$\begin{array}{l}\text { Recreational/Leisure- } \\
\text { time Physical Activity } \\
\qquad(\%(\mathrm{SE}))\end{array}$} & Inactive & $33.6(0.8)$ & $49.5(1.1)$ & \multirow{3}{*}{$<0.05$} \\
\hline & Somewhat active & $30.3(0.7)$ & $25.9(0.9)$ & \\
\hline & Active & $36.1(0.8)$ & $24.6(0.9)$ & \\
\hline Smoking (\% (SE)) & Past or current & $24.2(0.8)$ & $20.3(0.7)$ & $<0.05$ \\
\hline Alcohol (\% (SE)) & $\geq 3$ drinks per day & $36.7(0.9)$ & $32.7(1.1)$ & $<0.05$ \\
\hline \multirow{3}{*}{ BMI (\% (SE)) } & Normal weight & $46.5(0.7)$ & $9.1(0.5)$ & \multirow{3}{*}{$<0.05$} \\
\hline & Overweight & $35.6(0.7)$ & $32.3(0.8)$ & \\
\hline & Obese & $17.9(0.6)$ & $58.6(1.0)$ & \\
\hline \multirow{4}{*}{$\begin{array}{c}\text { Doctor diagnosed } \\
\text { cancer or malignancy } \\
(\%(\mathrm{SE}))\end{array}$} & Any-site & $7.0(0.4)$ & $12.0(0.5)$ & $<0.05$ \\
\hline & Breast & $0.9(0.1)$ & $1.7(0.2)$ & $<0.05$ \\
\hline & Prostate & $0.6(0.1)$ & $1.4(0.2)$ & $<0.05$ \\
\hline & Colon & $0.2(0.1)$ & $0.8(0.1)$ & $<0.05$ \\
\hline
\end{tabular}

Table 1: Characteristics of the U.S. adult population with and without metabolic syndrome. $\mathrm{p}<0.05$, two-sided t-test or Chi-square, as appropriate. Mean (SEM) for continuous and frequency (SE) for categorical variables. Physical Activity: Inactive is no reported physical activity data; somewhat active is $>0$ to $<500 \mathrm{MET} \mathrm{min} / \mathrm{week}$ Active is $\geq 500 \mathrm{MET}$ min/week (meeting physical activity guidelines). Metabolic Syndrome (MetS) is having $\geq 3$ of $W C \geq 102 \mathrm{~cm}$ (men) and, $\geq 88 \mathrm{~cm}$ (women), Triglyceride $\geq 1.69 \mathrm{mmol} / \mathrm{L}(\mathrm{mM})$, HDL-Cholesterol $<1.04$ (men), $1.29 \mathrm{mM}$ (women), blood pressure $\geq 130 / 85 \mathrm{mmHg}$ of either diastolic or systolic pressures, and fasting plasma glucose $\geq 5.6 \mathrm{mM}$, based on the Harmonized Criteria. No MetS is $<3$ of these components. WC is waist circumference, "or medication use for hypertension, diabetes, cholesterol" before ", based on the Harmonized..." HDL is high density lipid, and NS is not significant. Weighted N=96, 318, 456.

educational attainment and income, and were more likely to be nonHispanic white. The frequency of any-site, breast, prostate and colon cancers were also higher in the MetS vs. non-MetS groups ( 740 vs. 556 , 109 vs. 72,124 vs. 80 , and 65 vs. 30, respectively). On the other hand, adults without MetS were more likely to engage in "recreational/" to be consistent 'recreational/leisure-time', house/yard work-, and transportrelated physical activity. Prevalence's of past or current smoking, $\geq 3$ alcohols drinks/day, normal weight and overweight individuals were also significantly higher in the non-MetS group.

Figure 1 shows the distribution of the number of MetS components and MetS in the U.S. adult population. Overall, the prevalence of MetS was $38.1 \pm 0.7 \%$ [ $\leq 50$ years: $26.0 \pm 0.7 \%$ vs. $>50$ years: $56.4 \pm 0.9 \%, p<0.0001$ ], with no significant sex difference [M: $38.2 \pm 0.8 \%$; F: $37.9 \pm 0.9 \%]$. 
The distributions of MetS and the number of MetS components in adults with a history of any-site, breast, prostate, and colon cancers are shown in Figure 2. More than half the men and women with anysite cancer had MetS (Figure 2a), with higher prevalences in older (vs. younger) adults (Figure $2 \mathrm{~b}$ ). In persons with a history of any-site and site-specific cancers, generally those with 2 or 3 MetS components had the highest prevalence of any-site, prostate, post-menopausal and total breast cancers (Figure 2c, 2d). Due to a small sample size, only pooled analyses were presented for colon cancer, prostate cancer was limited to men, and breast cancer was limited to women. Consequently, the prevalences of MetS were $57.5 \pm 3.0 \%$ and $68.1 \pm 4.1 \%$ in those with prostate and colon cancers, respectively.
In the $>50 \mathrm{y}$ age group, the prevalence of any-site cancer in the subpopulation with MetS was $17.6 \pm 0.8 \%$. This prevalence ranged between 15.7-19.6\%, depending on the number of MetS components and was highest in those with all 5 criteria $(12.1 \%$ for men, $17.3 \%$ for women, and $4.7 \%$ for $\leq 50$ years old) (data not shown).

Table 2 contains the crude, age-adjusted and multivariable logistic regression models for the association between each cancer and individual MetS components, number of MetS components, and MetS overall. Once adjusted for age, all but the association between high blood glucose and low HDL for prostate cancer, and high blood glucose and colon cancer were abolished. These associations were further attenuated after multivariable adjustment (age, sex, ethnicity, income, education,
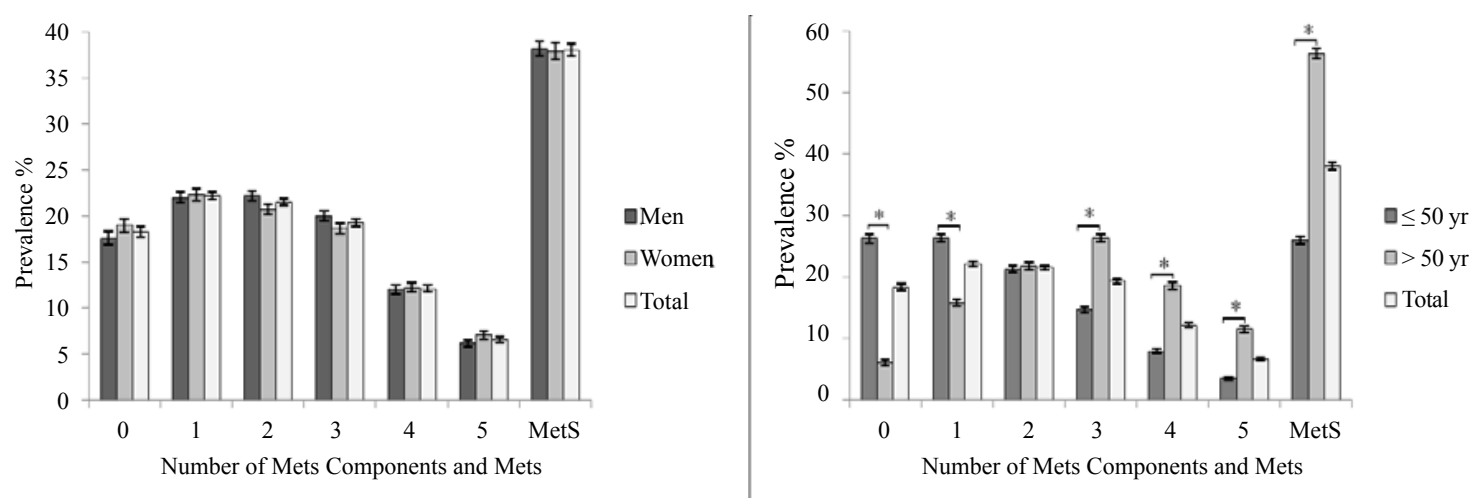

Figure 1: Prevalence of MetS and the number of MetS components in the US adult population a) by sex and b) age categories.
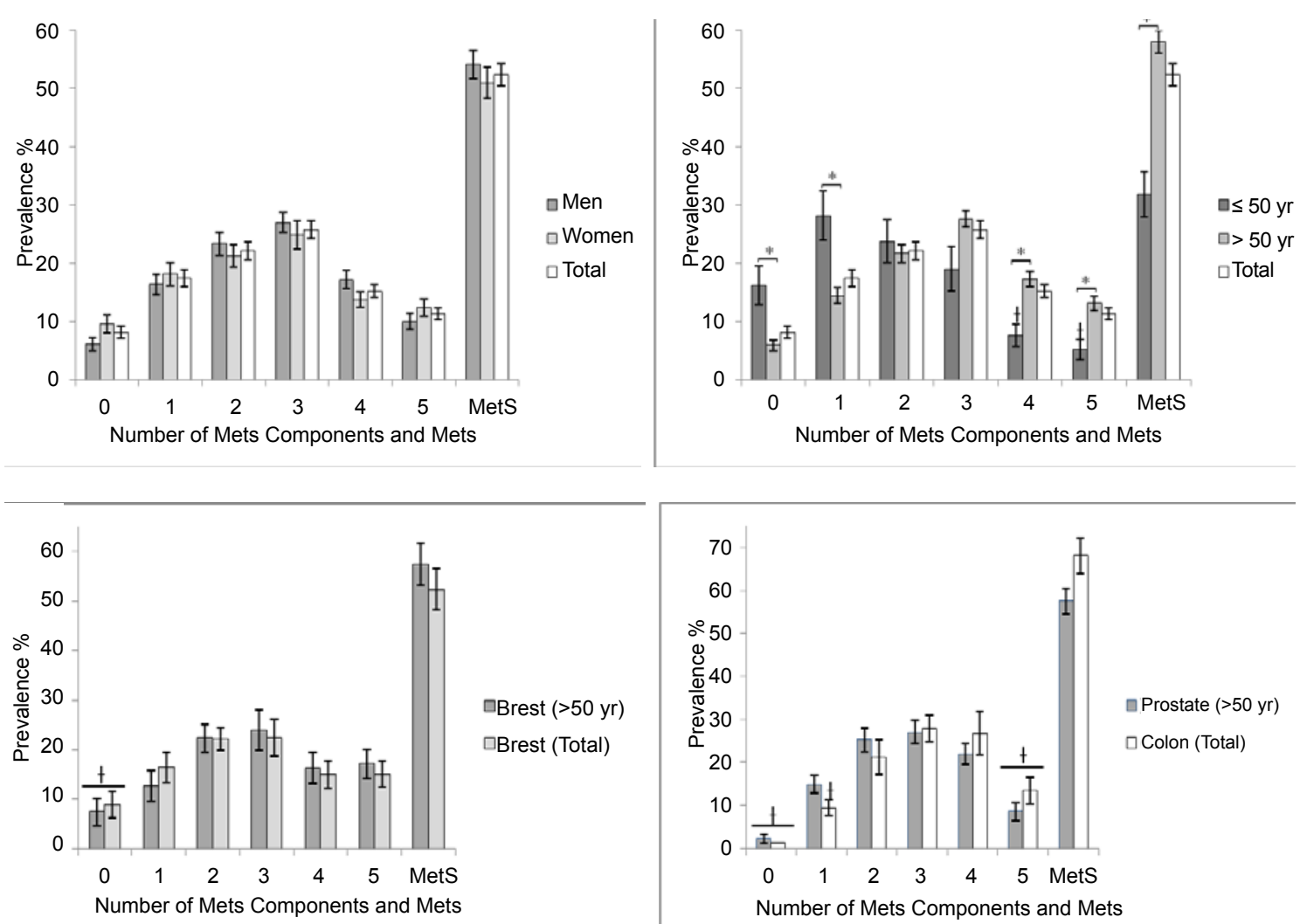

$\square$ Brest $(>50 \mathrm{yr})$

$\square$ Brest (Total)

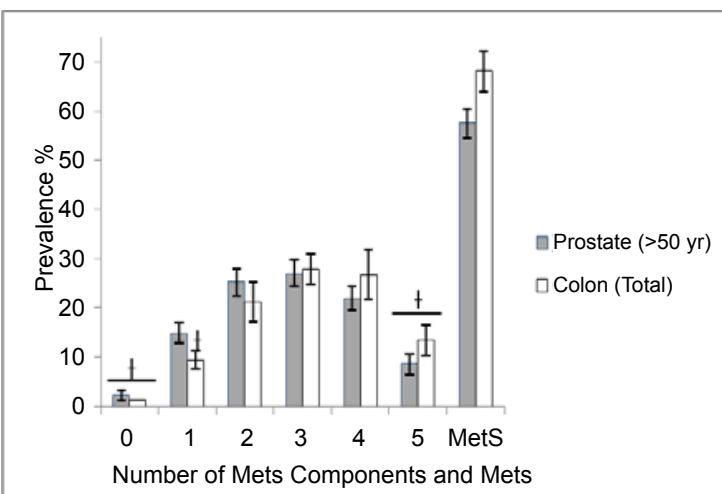

Figure 2a,b,c and d: Prevalence of MetS and the number of MetS components among the U.S. adult population with a) any-site cancer in men and women b) any-site cancer by age categories $\mathrm{c}$ ) postmenopausal and total breast cancer d) prostate and colon cancers. 


\begin{tabular}{|c|c|c|c|c|c|}
\hline & & \multicolumn{4}{|c|}{ Any-site $(n=1,296)$} \\
\hline & & ORc $(95 \% \mathrm{Cl})$ & ORage $(95 \% \mathrm{Cl})$ & ORadj $(95 \% \mathrm{Cl})$ & ORadj2 (95\% Cl) \\
\hline \multirow{5}{*}{$\begin{array}{l}\text { Individual MetS } \\
\text { components }\end{array}$} & High Blood Pressure & $2.57(2.24,2.94)^{\star}$ & $0.97(0.83,1.14)$ & $1.01(0.84,1.22)$ & $2.20(1.87,2.60)^{*}$ \\
\hline & High Glucose & $1.87(1.60,2.19)^{*}$ & $0.99(0.83,1.18)$ & $1.02(0.81,1.29)$ & $1.77(1.44,2.17)^{*}$ \\
\hline & Low HDL & $0.85(0.74,0.99)^{*}$ & $0.94(0.80,1.11)$ & $0.94(0.76,1.16)$ & $0.78(0.64,0.95)^{*}$ \\
\hline & High Triglyceride & $1.38(1.21,1.58)^{*}$ & $1.01(0.88,1.16)$ & $0.94(0.78,1.13)$ & $1.19(0.98,1.43)$ \\
\hline & High Waist Circumference & $1.56(1.32,1.84)^{*}$ & $1.10(0.92,1.30)$ & $1.05(0.83,1.32)$ & $1.37(1.09,1.71)^{*}$ \\
\hline \multirow{5}{*}{$\begin{array}{l}\text { Number of MetS } \\
\text { components }^{\S}\end{array}$} & 1 & $1.76(1.29,2.40)^{*}$ & $1.08(0.78,1.50)$ & $1.39(0.91,2.11)$ & $2.07(1.39,3.09)^{*}$ \\
\hline & 2 & $2.30(1.67,3.16)^{*}$ & $1.01(0.72,1.43)$ & $1.23(0.80,1.89)$ & $2.39(1.60,3.57)^{*}$ \\
\hline & 3 & $3.03(2.24,4.10)^{*}$ & $1.11(0.80,1.55)$ & $1.42(0.95,2.14)$ & $3.27(2.24,4.79)^{*}$ \\
\hline & 4 & $2.81(2.06,3.85)^{*}$ & $0.91(0.65,1.27)$ & $0.97(0.69,1.37)$ & $2.29(1.64,3.20)^{*}$ \\
\hline & 5 & $4.02(2.91,5.56)^{*}$ & $1.16(0.81,1.65)$ & $1.23(0.76,1.98)$ & $3.06(1.94,4.81)^{*}$ \\
\hline \multicolumn{2}{|c|}{$\mathrm{p}$ for linear trend } & $<0.0001$ & 0.0311 & 0.123 & $<0.0001$ \\
\hline \multirow{3}{*}{\multicolumn{2}{|c|}{ MetS\$\$ }} & $1.82(1.56,2.11)^{*}$ & $1.02(0.86,1.20)$ & $1.01(0.82,1.24)$ & $1.58(1.29,1.94)^{*}$ \\
\hline & & \multicolumn{4}{|c|}{ Breast $(n=181)$} \\
\hline & & ORc $(95 \% \mathrm{Cl})$ & ORage $(95 \% \mathrm{Cl})$ & ORadj $(95 \% \mathrm{Cl})$ & ORadj2 (95\% Cl) \\
\hline \multirow{5}{*}{$\begin{array}{l}\text { Individual MetS } \\
\text { components }\end{array}$} & High Blood Pressure & $3.15(2.05,4.84)^{*}$ & $0.81(0.49,1.33)$ & $0.76(0.41,1.42)$ & $2.26(1.30,3.91)^{*}$ \\
\hline & High Glucose & $2.25(1.64,3.10)^{*}$ & $1.04(0.73,1.46)$ & $0.68(0.42,1.10)$ & $1.26(0.79,2.02)^{*}$ \\
\hline & Low HDL & $0.91(0.59,1.41)$ & $0.94(0.62,1.43)$ & $0.92(0.53,1.59)$ & $0.76(0.44,1.32)$ \\
\hline & High Triglyceride & $1.87(1.34,2.63)^{*}$ & $1.13(0.80,1.58)$ & $0.96(0.57,1.62)$ & $1.34(0.80,2.23)$ \\
\hline & High Waist Circumference & $1.11(0.73,1.71)$ & $0.75(0.47,1.18)$ & $0.58(0.32,1.05)$ & $0.76(0.42,1.35)$ \\
\hline \multirow{5}{*}{$\begin{array}{l}\text { Number of MetS } \\
\text { components }^{\S}\end{array}$} & 1 & $1.57(0.67,3.67) \dagger$ & $0.81(0.32,2.05) \dagger$ & $0.82(0.28,2.36) \dagger$ & $1.51(0.59,3.81) \dagger$ \\
\hline & 2 & $2.30(1.03,5.12)^{*} t$ & $0.81(0.33,2.00) \dagger$ & $0.58(0.21,1.63) \dagger$ & $1.43(0.58,3.49) \dagger$ \\
\hline & 3 & $2.60(1.17,5.74)^{\star} t$ & $0.70(0.28,1.73) \dagger$ & $0.60(0.20,1.86) \dagger$ & $1.88(0.74,4.81) \dagger$ \\
\hline & 4 & $2.64(1.27,5.50)^{*}+$ & $0.61(0.26,1.41) \dagger$ & $0.32(0.11,0.92)^{\star} \dagger$ & $1.04(0.40,2.69) \dagger$ \\
\hline & 5 & $4.68(2.01,10.90)^{\star} \nmid$ & $0.91(0.34,2.41) \dagger$ & $0.66(0.17,2.48) \dagger$ & $2.19(0.66,7.35) \dagger$ \\
\hline \multicolumn{2}{|c|}{$p$ for linear trend } & 0.0011 & 0.0134 & 0.0011 & 0.7349 \\
\hline \multirow{3}{*}{\multicolumn{2}{|c|}{ MetS\$§ }} & $1.83(1.26,2.65)^{*}$ & $0.86(0.58,1.27)$ & $0.71(0.41,1.21)$ & $1.25(0.75,2.07)$ \\
\hline & & \multicolumn{4}{|c|}{ Prostate $(n=204)$} \\
\hline & & ORc $(95 \% \mathrm{Cl})$ & ORage $(95 \% \mathrm{Cl})$ & ORadj $(95 \% \mathrm{Cl})$ & ORadj2 (95\% Cl) \\
\hline \multirow{5}{*}{$\begin{array}{l}\text { Individual MetS } \\
\text { components }\end{array}$} & High Blood Pressure & $3.64(1.97,6.72)^{*}$ & $0.96(0.51,1.80)$ & $0.92(0.44,1.90)$ & $3.00(1.45,6.22)^{*}$ \\
\hline & High Glucose & $3.89(2.62,5.79)^{\star}$ & $1.67(1.08,2.56)^{\star}$ & $1.69(1.00,2.85)$ & $3.42(2.10,5.57)^{*}$ \\
\hline & Low HDL & $0.52(0.35,0.76)^{*}$ & $0.64(0.43,0.94)^{*}$ & $0.80(0.45,1.43)$ & $0.55(0.32,0.96)^{*}$ \\
\hline & High Triglyceride & $1.39(1.01,1.92)^{*}$ & $1.16(0.83,1.63)$ & $0.82(0.50,1.32)$ & $0.87(0.54,1.38)$ \\
\hline & High Waist Circumference & $2.10(1.51,2.91)^{\star}$ & $1.39(0.98,1.96)$ & $1.37(0.82,2.26)$ & $1.80(1.10,2.95)^{*}$ \\
\hline \multirow{5}{*}{$\begin{array}{l}\text { Number of MetS } \\
\text { components }^{\S}\end{array}$} & 1 & $5.46(1.72,17.32)^{\star} \nmid$ & $2.04(0.62,6.77) \dagger$ & $1.62(0.33,8.02) \dagger$ & $4.17(0.92,18.97) \dagger$ \\
\hline & 2 & $9.21(2.89,29.35)^{*}+$ & $2.04(0.61,6.82) \dagger$ & $1.84(0.37,8.99) \dagger$ & $7.16(1.55,32.96)^{*} t$ \\
\hline & 3 & $11.00(3.89,31.13)^{*} t$ & $2.21(0.74,6.59) \dagger$ & $1.69(0.44,6.50) \dagger$ & $7.25(2.05,25.64)^{*} \nmid$ \\
\hline & 4 & $14.95(5.21,42.91)^{*}$ & $2.68(0.88,8.18) \dagger$ & $2.04(0.43,9.71) \dagger$ & $8.05(1.91,33.92)^{*} t$ \\
\hline & 5 & $11.38(3.46,37.46)^{\star} t$ & $1.93(0.57,6.49) \dagger$ & $1.57(0.30,8.18) \dagger$ & $6.66(1.40,31.68)^{*} t$ \\
\hline \multicolumn{2}{|c|}{$\mathrm{p}$ for linear trend } & $<.0001$ & 0.9543 & 0.9257 & 0.0002 \\
\hline \multirow{3}{*}{\multicolumn{2}{|c|}{ MetS§§ }} & $2.23(1.61,3.08)^{*}$ & $1.20(0.86,1.66)$ & $1.06(0.67,1.68)$ & $1.67(1.06,2.61)^{*}$ \\
\hline & & \multicolumn{4}{|c|}{ Colon $(n=95)$} \\
\hline & & ORc $(95 \% \mathrm{Cl})$ & ORage $(95 \% \mathrm{Cl})$ & ORadj $(95 \% \mathrm{Cl})$ & ORadj2 (95\% Cl) \\
\hline \multirow{5}{*}{$\begin{array}{l}\text { Individual MetS } \\
\text { components }\end{array}$} & High Blood Pressure & $11.19(4.18,29.97)^{*}+$ & $2.43(0.92,6.42) \dagger$ & $1.53(0.51,4.56) \dagger$ & $6.01(1.87,19.27)^{*} \nmid$ \\
\hline & High Glucose & $3.82(2.39,6.11)^{\star}$ & $1.60(1.02,2.53)^{*}$ & $1.57(0.74,3.36) \dagger$ & $3.21(1.45,7.07)^{*} \mathrm{t}$ \\
\hline & Low HDL & $0.82(0.48,1.40)$ & $0.97(0.56,1.67)$ & $1.05(0.45,2.43) \dagger$ & $0.74(0.31,1.68) t$ \\
\hline & High Triglyceride & $2.03(1.38,2.98)^{*}$ & $1.36(0.92,2.02)$ & $1.39(0.74,2.63)$ & $1.67(0.86,3.21)$ \\
\hline & High Waist Circumference & $2.05(1.26,3.32)^{*}$ & $1.31(0.80,2.16)$ & $1.21(0.65,2.25) \dagger$ & $1.45(0.75,2.82) \dagger$ \\
\hline \multirow{5}{*}{$\begin{array}{l}\text { Number of MetS } \\
\text { components }^{\S}\end{array}$} & 1 & $6.28(0.78,50.69) \dagger$ & $2.20(0.26,18.46) \dagger$ & $1.39(0.15,13.16) \dagger$ & $4.15(0.49,34.95) \dagger$ \\
\hline & 2 & $14.67(1.92,112.04)^{*}+$ & $3.08(0.36,26.18) t$ & $1.55(0.15,16.54) \dagger$ & $6.97(0.83,58.49) \dagger$ \\
\hline & 3 & $21.42(2.91,157.89)^{*}+$ & $3.77(0.49,29.28) \dagger$ & $2.36(0.27,20.63) \dagger$ & $11.18(1.55,88.86)^{*} t$ \\
\hline & 4 & $32.88(4.28,252.89)^{*}+$ & $4.95(0.61,40.44) \dagger$ & $1.63(0.17,15.47) \dagger$ & $8.10(0.93,70.73) \dagger$ \\
\hline & 5 & $30.19(3.89234 .64)^{*} t$ & $3.83(0.47,31.26) t$ & $3.01(0.29,31.50) t$ & $13.84(1.29,148.17)^{*} t$ \\
\hline$p$ fo & ear trend & $<.0001$ & 0.3145 & 0.5796 & 0.0538 \\
\hline & $t S^{\S \S}$ & $3.49(2.09,5.84)^{*}$ & $1.62(0.98, .69)$ & $1.56(0.79,3.08)$ & $2.57(1.29,5.13)^{*}$ \\
\hline
\end{tabular}

Table 2: Odds ratios for any-site, breast, prostate and colon cancers by individual MetS components, number of MetS components and MetS for the U.S. adult population ORc is odds ratio crude, ORage is odds ratio adjusted for age, ORadj is odds ratio adjusted for age, sex, ethnicity, income, education, smoking, alcohol, and recreational/ leisure-time physical activity (for breast and prostate cancers, sex was not included in the model), and ORadj2 is odds ratio adjusted for sex, ethnicity, income, education, smoke, alcohol, and recreational/leisure-time physical activity (for breast and prostate cancers, sex was not included in the model). Metabolic Syndrome (MetS) is having $\geq 3$ of Waist Circumference $\geq 102 \mathrm{~cm}$ (men) and, $\geq 88 \mathrm{~cm}$ (women), Triglyceride $\geq 1.69 \mathrm{mmol} / \mathrm{L}$ (mM), HDL-Cholesterol < 1.04 (men), $1.29 \mathrm{mM}$ (women), blood pressure $\geq$ $130 / 85 \mathrm{mmHg}$ of either diastolic or systolic pressures, and fasting plasma glucose $\geq 5.6 \mathrm{mM}$, "or medication use for hypertension, diabetes, cholesterol" before ", based on the Harmonized...". \&compared to 0 MetS components, ${ }^{\S}$ compared to no MetS, tinterpret with caution as $n<20$ in reference or response group; * $p<0.05 . G e n e r a l$ linear model was used to determine the $\mathrm{p}$ for trend analysis. Note: those with missing data were excluded from logistic analyses, and all data have been weighted to represent the U.S. adult population. 
smoking, alcohol, and recreational/leisure-time physical activity). Although there was a linear-dose response relationship between the number of MetS components and cancer, the relationship was no longer significant after adjusting for covariates. The only remaining linear trend was for breast cancer, which must be interpreted with caution due to a small sample across the number of MetS components.

To explore age-differences in the above relationships, analyses were stratified by age $(18-50$ y vs. $>50$ y). After stratification, the only remaining significant associations were for number of MetS components with prostate and colon cancer (Table 3).

\section{Discussion}

Our aim was to quantify the associations between the number and composition of MetS clusters and any-site, breast, prostate and colon cancers. In general, we found that individuals with MetS had higher prevalences of any-site, breast, prostate, and colon cancers. However, after adjustment for confounders, these relationships were no longer significant. Similarly, despite a graded dose-response relationship for the number of MetS components and prevalence of site-specific cancers, no consistent associations remained after multivariable adjustment.

Our estimation of MetS prevalence is slightly higher than other studies (38\% vs. $34 \%$ ) using similar data and definition, a finding that may be attributed in part to our exclusion of participants with any missing MetS components, and variation in NHANES data cycles
$[1,2]$. MetS prevalence increases gradually with time, and since we used newer data, this may further explain our modestly higher prevalence [26]. Nonetheless, cancer prevalence in our study (any-site: $8.96 \%$; breast: $1.22 \%$; prostate: $0.94 \%$; and colon: $0.43 \%$ ) is similar to previous estimates, with slight variation owing to differences in sample selection criteria [27].

\section{MetS Components and Site-Specific Cancer}

The above notwithstanding, our finding of no association between MetS and site-specific cancers is at odds with some, but not all previous work. For breast cancer, our finding of no significant association with further stratification by age and menopausal status (i.e., $>50 \mathrm{y}$ ) is in contrast to the finding of elevated risk amongst those with MetS (1.58, 1.07-2.33) or its individual components $(1.67,1.06-2.63)$ reported elsewhere. On the other hand, null associations between diabetes, hypertension and dyslipidemia and breast cancer are not entirely unexpected, and have been found in other studies [10,18,21,28]. Variations in the multivariable model, selection criteria, innate characteristics of the study population and study design may account for some of the observed inconsistencies.

The relationship between MetS and prostate cancer also yielded inconsistent results. In our study, low HDL was associated with $36 \%$ lower odds of prostate cancer. By contrast, a hospital-based case control by Magura et al. found that men with low HDL cholesterol $(<1.03 \mathrm{mM})$

\begin{tabular}{|c|c|c|c|c|}
\hline & & \multicolumn{3}{|c|}{ OR $(95 \% \mathrm{Cl})$} \\
\hline & & \multicolumn{2}{|c|}{ Any-site $(n=1296)$} & \\
\hline & & \multicolumn{2}{|l|}{$\leq 50$ years $(n=195)$} & $>50$ years $(n=1101)$ \\
\hline \multirow{5}{*}{ Individual MetS component } & High Blood Pressure & \multicolumn{2}{|l|}{$1.42(1.04,1.95)^{\star}$} & $1.30(1.08,1.56)^{*}$ \\
\hline & High Glucose & \multicolumn{2}{|l|}{$1.11(0.74,1.66)$} & \\
\hline & Low HDL & $0.94(0.66,1.35)$ & $1.15(0.96,1.38)$ & , 1.08) \\
\hline & High Triglyceride & $1.20(0.89,1.61)$ & \multicolumn{2}{|c|}{$1.01(0.85,1.20)$} \\
\hline & High Waist Circumference & \multirow{2}{*}{$\begin{array}{c}1.62(1.17,2.26)^{*} \\
1.71(0.97,2.99)\end{array}$} & \multicolumn{2}{|c|}{$0.98(0.82,1.17)$} \\
\hline \multirow{5}{*}{ Number of MetS components $\S$} & 1 & & \multicolumn{2}{|c|}{$0.94(0.62,1.43)$} \\
\hline & 2 & $\begin{array}{l}1.11(0.99,2.99) \\
1.74(0.99,3.04)\end{array}$ & \multicolumn{2}{|c|}{$1.04(0.70,1.53)$} \\
\hline & 3 & $2.00(1.07,3.76)$ & \multicolumn{2}{|c|}{$1.10(0.75,1.62)$} \\
\hline & 4 & $1.46(0.76,2.79) \dagger$ & \multicolumn{2}{|c|}{$0.96(0.63,1.46)$} \\
\hline & 5 & $2.28(0.99,5.24) \dagger$ & \multicolumn{2}{|c|}{$1.23(0.81,1.86)$} \\
\hline \multicolumn{2}{|c|}{$\mathrm{p}$ for linear trend } & 0.1808 & & 0.8029 \\
\hline \multicolumn{2}{|c|}{ MetS§§ } & $1.27(0.90,1.81)$ & & $1.08(0.92,1.28)$ \\
\hline & & Breast & Prostate & Colon \\
\hline & & $>50$ years $(n=166)$ & $>50$ years $(n=204)$ & $>50$ years $(n=90)$ \\
\hline \multirow{5}{*}{ Individual MetS component } & High Blood Pressure & $1.35(0.81,2.26)$ & $1.38(0.76,2.50)$ & $6.78(2.34,19.60)^{*}$ \\
\hline & High Glucose & $1.20(0.85,1.69)$ & $1.76(1.17,2.64)^{\star}$ & $2.01(1.25,3.25)^{*}$ \\
\hline & Low HDL & $0.91(0.59,1.41)$ & $0.61(0.42,0.89)$ & $0.95(0.55,1.66)$ \\
\hline & High Triglyceride & $1.19(0.84,1.68)$ & $1.06(0.76,1.46)$ & $1.23(0.78,1.93)$ \\
\hline & High Waist Circumference & $0.73(0.47,1.13)$ & $1.19(0.86,1.66)$ & $1.21(0.70,2.08)$ \\
\hline \multirow{5}{*}{ Number of MetS components $\$$} & 1 & $0.63(0.23,1.67) \dagger$ & $2.79(0.88,8.81) \dagger$ & $2.59(0.31,21.71) \dagger$ \\
\hline & 2 & $0.92(0.36,2.36) t$ & $3.00(0.94,9.58) t$ & $3.81(0.50,29.23) \dagger$ \\
\hline & 3 & $0.77(0.31,1.89) \dagger$ & $2.76(0.96,7.92) t$ & $5.25(0.70,39.20) t$ \\
\hline & 4 & $0.68(0.29,1.61) \dagger$ & $3.52(1.20,10.27)^{\star} \mathrm{f}$ & $6.94(0.88,54.56) \dagger$ \\
\hline & 5 & $1.06(0.37,3.08) \dagger$ & $2.62(0.80,8.56) \dagger$ & $5.50(0.69,43.96) \dagger$ \\
\hline \multicolumn{2}{|c|}{$p$ for linear trend } & 0.4133 & $0.0254^{*}$ & $0.0078^{*}$ \\
\hline \multicolumn{2}{|c|}{ MetS ${ }^{\S \S}$} & $0.99(0.66,1.49)$ & $1.12(0.82,1.55)$ & $1.97(1.21,3.19)^{*}$ \\
\hline
\end{tabular}

Table 3: Age-stratified association between individual MetS components, number of MetS components and MetS and any-site, breast and colon cancers, OR is crude odds ratio. Metabolic Syndrome (MetS) is having $\geq 3$ of WC $\geq 102 \mathrm{~cm}$ (men) and, $\geq 88 \mathrm{~cm}$ (women), Triglyceride $\geq 1.69 \mathrm{mmol} / \mathrm{L}$ (mM), HDL-Cholesterol $<1.04$ (men), 1.29 $\mathrm{mM}$ (women), blood pressure $\geq 130 / 85 \mathrm{mmHg}$ of either diastolic or systolic pressures, and fasting plasma glucose $\geq 5.6 \mathrm{mM}$, "or medication use for hypertension, diabetes, cholesterol" before ", based on the Harmonized...". ${ }^{\circledR}$ compared to 0 MetS components, ${ }^{\S}$ compared to no MetS, tinterpret with caution as $n<20$ in reference or response group; ${ }^{*} p<0.05$. Due to small number of site-specific cancers among $\leq 50$ year, only results for $>50$ years are shown for age stratification. Note: those with missing data were excluded from logistic analyses, and all data have been weighted to represent the U.S. adult population but $n$ of samples used in weighing are given. 
had a 57\% (1.04-2.36) greater likelihood of prostate cancer compared to those with high HDL [29]. Two other studies using cohort designs have produced null associations [20,30]. Although we report a positive association between high blood glucose and prostate cancer, null and negative associations amongst older men and certain ethnic groups (RR: 0.65 [95\% CI: 0.50-0.84] for European Americans, RR: 0.89 [95\% CI: 0.77-1.03] for African Americans) have also been found [12,20,31]. Differences in blood glucose level (i.e., high glucose $(\geq 5.6 \mathrm{mM})$ vs. diabetes $(\geq 11.1 \mathrm{mM})$ ) may have exaggerated these differences, as only 22 of 204 prostate cancer cases had physician diagnosed diabetes in our study. Given the central role of obesity in MetS and its high prevalence in the US population, it is also possible that duration of obesity (or elevated blood glucose) may be an important factor in prostate cancer development through oxidative stress induced cell proliferation, reduced adiponectin levels, and hyperinsulinemia induced prostate/ colon cancer cell proliferation $[3,4,32,33]$. When taken together, the discrepancy between the findings may be due to variation in: i) confounding variables and sample (i.e. hospital-based vs. nationally representative); ii) classification of past and current smokers; and iii) multivariable adjustment.

\section{Number of MetS Components and Cancer}

Studies evaluating the linear dose-response relationship between the number of MetS components and colorectal, colon, prostate, and postmenopausal breast cancers have found mixed results [17-22]. Contrary to some but not all studies, our linear trends were generally insignificant. Despite pooling multiple cycles of NHANES, the sample size available to explore the dose-response relationship between sitespecific cancers and number of MetS components was small, and results must be interpreted with caution $[17,18,20,21]$.

Once more, while the general pattern crude analyses was suggestive of a relationship between number of MetS clusters and any-site cancer, these associations were almost entirely reversed by age, a phenomenon known as Simpson's paradox [34-36]. Cancer risk progressively increases with age and may be linked to age-related increases in susceptibility to carcinogens, hormonal imbalance, immunologic dysfunction, and decreased capacity for cell repair/apoptosis [37]. Although several experimental studies have reported the Simpson's paradox of age, we are not aware of any population-based study that has reported the Simpson's paradox of age between cancer and MetS or its composition. Furthermore, since our results suggest that age is on the causal pathway between metabolic dysfunction and cancer, it is not a genuine confounder $[34,38]$. Taken together, these findings reinforce therapeutic and preventive strategies targeting age-related causal mechanisms such as immunological decline [39].

\section{Limitations}

First, given that our analysis is limited to cross-sectional data, cause and effect cannot be inferred. Second, because only cancer survivors are included, results may be an underestimate of the true association between MetS and cancer [40]. Finally, it is possible that changes in behaviour (consequent to cancer diagnosis) and the self-reported nature of lifestyle factors and cancer history may have also contributed to a lack of observed associations.

\section{Conclusions}

Significant crude association between the number (or composition) of MetS clusters and any-site, breast, prostate, and colon cancers are present, but accounting for age alone attenuated most of the associations. In light of the strong effect of age on these associations, additional prospective studies are needed to explore the effects of MetS components on the development and prognosis of obesity-related cancers.

\section{Reference}

1. Mozumdar A, Liguori G (2011) Persistent Increase of Prevalence of Metabolic Syndrome Among U.S. Adults: NHANES III to NHANES 1999-2006. Diabetes Care 34: 216-219.

2. Ford ES, Li C, Zhao G (2010) Prevalence and correlates of metabolic syndrome based on a harmonious definition among adults in the US. J Diabetes 2: 180 193.

3. Khandekar MJ, Cohen P, Spiegelman BM (2011) Molecular mechanisms of cancer development in obesity. Nat Rev Cancer 11: 886-895.

4. Wolin KY, Carson K, Colditz GA (2010) Obesity and Cancer. The Oncologist 15: $556-565$.

5. Cowey S, Hardy RW (2006) The metabolic syndrome: A high-risk state for cancer? Am J Pathol 169: 1505-1522.

6. Calle EE, Kaaks R (2004) Overweight, obesity and cancer: epidemiological evidence and proposed mechanisms. Nat Rev Cancer 4: 579-591.

7. Jin K (2010) Modern Biological Theories of Aging. Aging Dis 1: 72-74.

8. Kim RB, Phillips A, Herrick K, Helou M, Rafie C, et al. (2013) Physical activity and sedentary behavior of cancer survivors and non-cancer individuals: results from a national survey. PLoS One 8: e57598.

9. Esposito K, Chiodini P, Colao A, Lenzi A, Giugliano D (2012) Metabolic syndrome and risk of cancer: a systematic review and meta-analysis. Diabetes Care 35: 2402-2411.

10. Larsson SC, Mantzoros CS, Wolk A (2007) Diabetes mellitus and risk of breast cancer: a meta-analysis. Int J Cancer 121: 856-862.

11. Larsson SC, Orsini N, Wolk A (2005) Diabetes mellitus and risk of colorectal cancer: a meta-analysis. J Nat Cancer Inst 97: 1679-1687.

12. Kasper JS, Giovannucci E (2006) A meta-analysis of diabetes mellitus and the risk of prostate cancer. Cancer Epidemiol Biomarkers Prev 15: 2056-2062.

13. Bellamy L, Casas JP, Hingorani AD, Williams DJ (2007) Pre-eclampsia and risk of cardiovascular disease and cancer in later life: systematic review and metaanalysis. BMJ 335: 974.

14. Larsson SC, Wolk A (2007) Obesity and colon and rectal cancer risk: a metaanalysis of prospective studies. Am J Clin Nutr 86: 556-565

15. Berrington de Gonzalez A, Sweetland S, Spencer E (2003) A meta-analysis of obesity and the risk of pancreatic cancer. Br J Cancer 89: 519-523.

16. Guh DP, Zhang W, Bansback N, Amarsi Z, Birmingham CL, et al. (2009) The incidence of co-morbidities related to obesity and overweight: a systematic review and meta-analysis. BMC Public Health 9: 88.

17. Ahmed RL, Schmitz KH, Anderson KE, Rosamond WD, Folsom AR (2006) The metabolic syndrome and risk of incident colorectal cancer. Cancer 107: 28-36.

18. Agnoli C, Berrino F, Abagnato CA, Muti P, Panico S, et al. (2010) Metabolic syndrome and postmenopausal breast cancer in the ORDET cohort: a nested case-control study. Nutr Metab Cardiovasc Dis 20: 41-48.

19. Tsilidis KK, Brancati FL, Pollak MN, Rifai N, Clipp SL, et al. (2010) Metabolic syndrome components and colorectal adenoma in the CLUE II cohort. Cancer Causes Control 21: 1-10.

20. Tande AJ, Platz EA, Folsom AR (2006) The metabolic syndrome is associated with reduced risk of prostate cancer. Am J Epidemiol 164: 1094-1102.

21. Rosato V, Bosetti C, Talamini R, Levi F, Montella M, et al. (2011) Metabolic syndrome and the risk of breast cancer in postmenopausal women. Ann Oncol 22: $2687-2692$

22. Pelucchi C, Negri E, Talamini R, Levi F, Giacosa A, et al. (2010) Metabolic syndrome is associated with colorectal cancer in men. Eur J Cancer 46: 18661872.

23. Alberti KGMM, Eckel RH, Grundy SM, Zimmet PZ, Cleeman JI, et al. (2009) Harmonizing the Metabolic Syndrome A Joint Interim Statement of the International Diabetes Federation Task Force on Epidemiology and Prevention: National Heart, Lung, and Blood Institute; American Heart Association; World Heart Federation; International Atherosclerosis Society; and International Association for the Study of Obesity. Circulation 120: 1640-1645. 
Citation: Kanagasabai T, Nie JX, Mason C, Ardern Cl (2014) Metabolic Syndrome and Prevalent Any-site, Prostate, Breast and Colon Cancers in the U.S. Adult Population: NHANES 1999-2010. J Metabolic Synd 3: 135. doi:10.4172/2167-0943.1000135

24. Penaranda EK, Shokar N, Ortiz M (2013) Relationship between Metabolic Syndrome and History of Cervical Cancer among a US National Population. ISRN Oncol 2013: 840964

25. Janssen I, Carson V, Lee IM, Katzmarzyk PT, Blair SN (2013) Years of life gained due to leisure-time physical activity in the U.S. Am J Prev Med 44: 2329.

26. Ford ES, Giles WH, Mokdad AH (2004) Increasing prevalence of the metabolic syndrome among u.s. Adults. Diabetes Care 27: 2444-2449.

27. Howlader N, Noone AM, Krapcho M, Garshell J, Neyman N, et al. (2013) SEER Cancer Statistics Review, 1975-2010, National Cancer Institute. Bethesda, MD.

28. Kucharska-Newton AM, Rosamond WD, Mink PJ, Alberg AJ, Shahar E, et al. (2008) HDL-cholesterol and incidence of breast cancer in the ARIC cohor study. Ann Epidemiol 18: 671-677.

29. Magura L, Blanchard R, Hope B, Beal JR, Schwartz GG, et al. (2008) Hypercholesterolemia and prostate cancer: a hospital-based case-control study. Cancer Causes Control 19: 1259-1266.

30. Mondul AM, Weinstein SJ, Virtamo J, Albanes D (2011) Serum total and HDL cholesterol and risk of prostate cancer. Cancer Causes Control 22: 1545-1552.

31. Waters KM, Henderson BE, Stram DO, Wan P, Kolonel LN, et al. (2009) Association of diabetes with prostate cancer risk in the multiethnic cohort. Am J Epidemiol 169: 937-945.
32. Doyle SL, Donohoe CL, Lysaght J, Reynolds JV (2012) Visceral obesity, metabolic syndrome, insulin resistance and cancer. Proc Nutr Soc 71: 181-189.

33. Su LJ, Arab L, Steck SE, Fontham ET, Schroeder JC, et al. (2011) Obesity and prostate cancer aggressiveness among African and Caucasian Americans in a population-based study. Cancer Epidemiol Biomarkers Prev 20: 844-853.

34. Julious SA, Mullee MA (1994) Confounding and Simpson's paradox. BMJ 309 1480-1481.

35. Tu YK, Gunnell D, Gilthorpe MS (2008) Simpson's Paradox, Lord's Paradox and Suppression Effects are the same phenomenon--the reversal paradox. Emerg Themes Epidemiol 5: 2.

36. Yancik R, Ries LA (1994) Cancer in older persons. Magnitude of the problem-how do we apply what we know? Cancer 74: 1995-2003.

37. Ukraintseva S, Yashin Al. (2003) Individual Aging and Cancer Risk: How are They Related? Demogr Res 9: 163-196.

38. Ameringer S, Serlin RC, Ward S (2009) Simpson's paradox and experimenta research. Nurs Res 58: 123-127.

39. DePinho RA (2000) The age of cancer. Nature 408: 248-254.

40. Courneya KS, Katzmarzyk PT, Bacon E (2008) Physical activity and obesity in Canadian cancer survivors: population-based estimates from the 2005 Canadian Community Health Survey. Cancer 112: 2475-2482. 